\title{
Autonomic Nervous System Dysregulation in Human Hypertension
}

\author{
Stevo Julius, MD, DSC
}

\begin{abstract}
An increased sympathetic drive combined with decreased parasympathetic inhibition is found in patients with borderline hypertension, who characteristically have rapid heart rates, high cardiac output and relatively normal vascular resistance (hyperkinetic state). In established hypertension, cardiac output is normal, vascular resistance is elevated and signs of increased sympathetic drive are absent. Apparently hemodynamics and sympathetic drive change during hypertension.
\end{abstract} The mechanism of the hemodynamic transition in the course of hypertension is well understood. Cardiac output returns from elevated to normal values as $\beta$-adrenergic receptors down-regulale and stroke volume decreases (due to decreased cardiac compliance). The high blood pressure induces vascular hypertrophy, which in turn leads to increased vascular resistance. The mechanism of the change of sympathetic tone from elevated in borderline hypertension to apparently normal in established hypertension can best be explained within the conceptual framework of the "blood-pressure-seeking" properties of the brain. In hypertension, the central nervous system seeks to maintain systemic blood pressure at the higher level. As hypertension advances and vascular hypertrophy develops, arterioles become hyperresponsive to vasoconstriction. At this point, less sympathetic drive is needed to maintain pressure-elovating vasoconstriction, and the central sympathetic drive is down-regulated. The etiology of increased sympathetic drive in hypertension remains unresolved. Subjects with increased sympathetic drive are also usually overweight and have elevated levels of insulin, cholesterol and triglycerides, as well as decreased high-density lipoproteins. Future re-

From the Department of Internal Medicine, University of Michigan, Division of Hypertension, Taubman Center, Ann Arbor, Michigan.

Address for reprints: Stevo Julius, MD, DSc, University of Michigan Hospitals, Division of Hypertension, 3918 Taubman Center, Ann Arbor, Michigan 48109-0356. search must focus on the link between coronary risk factors and sympathetic overactivity in hypertension.

(Am J Cardiol 1991;67:3B-7B)

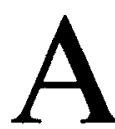
$t$ first glance, studies of the role of the autonomic nervous system (ANS) in human hypertension yield somewhat controversial results. An abnormality is easily demonstrated in young patients with borderline hypertension, but when older patients with established hypertension are studied, there is very little evidence for ANS dysregulation. This raises a number of questions: are young subjects with borderline hypertension a separate subgroup who either do not develop established hypertension, or, if they develop established hypertension, is the condition so rare that it cannot be distinguished from the larger pool of subjects who have a non-neurogenic established hypertension? If subjects with neurogenic borderline hypertension later develop established hypertension, why is it so difficult to show an autonomic abnormality in established hypertension? Does this mean that the ANS initiates hypertension but later does not play a role in its maintenance? What is the mechanism of transition from an apparently neurogenic to a seemingly non-neurogenic form of hypertension?

The purpose of this article is to review the evidence about the role of the ANS in hypertension and to provide answers to some of the questions.

\section{AUTONOMIC ABNORMALITY IN BORDERLINE HYPERTENSION}

The stimulus to study the role of the ANS in borderline hypertension comes from observation of the characteristic "hyperkinetic" hemodynamics, consisting of a high cardiac output, fast heart rate and increased stroke volume. ${ }^{1-5}$ Brod $^{6}$ suggested that this picture resembles the hemodynamic state during emotional excitementthe so-called "fight or flight" reaction. Whether the hemodynamic pattern in borderline hypertension is indeed due to an emotional response remains unresolved. However, it has been shown without a doubt that an autonomic dysregulation is the basic mechanism in borderline hypertension, because cardiac "denervation" by auto- 
nomic blockade abolishes the increase of cardiac output that occurs in this state. ${ }^{7}$

An increased sympathetic tone in borderline hypertension has been documented by different cxperimental methods. An increased rate of bursts of activity in the sympathetic fibers of the peroneal nerves has been demonstrated with direct microneurographic recordings in cases of borderline hypertension. ${ }^{8}$ Plasma norepinephrine levels in such patients are elevated. ${ }^{9}$ Studies with radioisotope tracers found increased norepinephrine spillover rates in young subjects with mild hypertension. ${ }^{10}$ Sympathetic tone can also be assessed by spectral analysis of the electrocardiogram, and increased sympathetic activity in mild hypertension has been found by that method. ${ }^{11}$

Increased sympathetic tone in borderline hypertension is coupled with a decrease in parasympathetic activity. Intravenous atropine elicits a smaller increase of heart rate and cardiac output in borderline hypertension, suggesting that, compared with normotensive subjects, borderline hypertensive subjects have less cardiac parasympathetic inhibition. ${ }^{7}$ Spectral analysis of the heart rate yields a similar picture of decreased parasympathetic tone in mild hypertension. ${ }^{11}$ Decreased parasympathetic tone is evident also in noncardiovascular regions. In studies of patients with borderline hypertension, Bohm et al $^{12}$ found a significant reduction of the parasympathetically mediated salivary flow rates.

Since the reciprocal coupling of the sympathetic and parasympathetic tone characteristically occurs at the level of cardiovascular centers in the medulla oblongata, the inverse relationship of sympathetic and parasympathetic tone in borderline hypertension suggests that the autonomic abnormality is of central nervous system (CNS) origin. As one would expect with central derangement, the autonomic abnormality in borderline hypertension is widespread. Alpha-adrenergic drive to the arterioles is increased, ${ }^{13}$ particularly in borderline hypertensives, who also have higher plasma renin activity. We speculated that this high renin may reflect an enhanced renal $\beta$ adrenergic drive in borderline hypertension. ${ }^{14}$ This notion has been confirmed by Esler et al, ${ }^{15}$ who found a substantial enhancement of the regional renal spillover of norepinephrine in borderline hypertension. Two other abnormalities, decreased plasma volume ${ }^{16}$ and increased venous tone ${ }^{17,18}$ in borderline hypertension, can also be explained by an increased sympathetic tone.

\section{EVIDENCE THAT NEUROGENIC BORDERLINE HYPERTENSION LEADS TO ESTABLISHED HYPERTENSION}

Subjects with borderline hypertension are at a higher risk of developing more severe forms of hypertension, but that risk is not overwhelming. Over the course of 20 years it is likely that about $70 \%$ of young subjects with borderline hypertension will not progress to permanent, established hypcrtension. ${ }^{19}$ Therefore, it is important to determine the prognosis specifically for subjects with neurogenic borderline hypertension. In clinical practice there is good evidence that the hyperkinetic state, which is demonstrably associated with increased sympathetic stimulation and decreased vagal inhibition of the sinus node, is a precursor of future hypertension. A fast heart rate in youth is a predictor of future hypertension. ${ }^{20-22}$ Longitudinal studies also indicate that the underlying hemodynamics evolve from a hyperkinetic state of high cardiac output into a state of increased vascular resistance. ${ }^{23,24}$ This evolution from hyperkinetic-borderline hypertension to increased-vascular-resistance clinical hypertension requiring treatment has been demonstrated by Lund-Johansen and Omvik. ${ }^{25}$ In a unique study, these investigators followed and repeatedly studied a group of subjects with borderline hypertension over a period of 20 years. After 10 years, the hemodynamics changed from high cardiac output to high resistance, but the baseline blood pressure did not increase. After 20 years, the majority of previously borderline subjects developed clinical hypertension due to a further increase of the vascular resistance. The decrease of cardiac output after 20 years was mediated by both a lower heart rate and a decrease of stroke volume.

\section{MECHANISM OF HEMODYNAMIC TRANSITION}

Hemodynamic autoregulation is the ability of an organ to maintain a steady, optimal flow by varying its resistance. "Total body autoregulation" is one mechanism that could decrease the cardiac output and increase the vascular resistance in the course of developing hypertension. The concept of total body autoregulation proposed by Guyton and Coleman ${ }^{26}$ describes hemodynamic events observed after volume expansion. In partially nephrectomized animals, salt and water overload leads to increased cardiac output. This elevated flow exceeds the metabolic needs of various organs in the body and triggers an autoregulatory increase of vascular resistance and a higher blood pressure. The higher pressure causes enhanced diuresis, which in turn leads to restitution of a normal blood volume and a return of the cardiac output into the normal range.

In borderline hypertension, it is likely that this sequence fails to occur. Whereas renal sympathetic activation in borderline hypertension may lead to a tendency for acute fluid retention, ${ }^{27}$ there is no evidence for a volume expansion in borderline hypertension. On the contrary, plasma volume in borderline hypertension is 
decreased. ${ }^{28}$ Further, total body autoregulation is triggered only under conditions of "luxury perfusion," e.g., when the flow exceeds the metabolic demands of the body. The relationship between basal flow and metabolic demands in humans can be assessed from the relationship between cardiac output and resting oxygen consumption. In patients with hyperkinetic borderline hypertension, both the cardiac output and oxygen consumption are elevated. ${ }^{3-5}$ Under these conditions the stimulus for total body autoregulation is absent.

Transition from a high cardiac output to a high resistance state in the course of hypertension can best be explained by altered target organ responsiveness. Prolonged exposure to increased sympathetic drive decreases the chronotropic and inotropic $\beta$-adrenergic responsiveness of the heart. ${ }^{29,30} \mathrm{~A}$ decrease of $\beta$-adrenergically mediated vasodilation in hypertension has also been reported. ${ }^{31}$ A further mechanism that, combined with decreased $\beta$-adrenergic responsiveness, may lead to the normalization of the cardiac output in the course of hypertension, is a decrease of stroke volume. LundJohansen ${ }^{4}$ found that subjects with borderline hypertension do not adequately increase their stroke volume during exercise. The limitation of the stroke volume is particularly evident in the "normokinetic" (normal cardiac output) subgroup of patients with borderline hypertension. Such patients have lower than normal resting stroke volume, and this decrease is greatly accentuated after autonomic blockade of the heart with injections of propranolol and atropine. ${ }^{29}$ The stroke volume in such a "denervated" heart depends solely on the end diastolic stretch. Since cardiac filling, evidenced by total blood volume and the cardiopulmonary portion of the blood volume, were not decreased, a pressure-induced decrease in cardiac compliance is most likely responsible for low stroke volume in these patients.

The same factors that lead to lower cardiac output are also conducive to the progressive elevation of vascular resistance in the course of hypertension. Longstanding blood pressure elevation causes hypertrophy of the medial layer of the arteriolar wall. The thicker media encroaches upon the lumen of the vessel, thereby changing the wall to lumen ratio. During vasoconstriction, the wall of the hypertrophic resistance vessels encroaches upon the lumen even more than in the relaxed state, and the increase of resistance is greatly exaggerated. This renders the resistance vessels hyperresponsive to all vasoconstrictive stimuli, a sequence described in detail by Folkow. ${ }^{32}$ The degree of cardiac and vascular hypertrophy depends also on various "trophic" factors in addition to blood pressure. Sympathetic stimulation is a recognized vascular trophic factor, ${ }^{33}$ and increased vasomotor tone in borderline hypertension may be, in its own right, condu- cive to early vascular hypertrophy. The presence of an altered wall to lumen ratio in the early phases of hypertension has been well documented ${ }^{34}$ and these changes contribute to the maintenance of increased vascular resistance. It is conceivable that the enhanced vascular resistance is also due in part to decreased $\beta$ - and enhanced $\alpha$ adrenergic responsiveness, as proposed by Buhler et al. ${ }^{31}$

\section{DECREASE OF SYMPATHETIC TONE IN THE COURSE OF HYPERTENSION}

Decreased $\beta$-adrenergic responsiveness and decreased stroke volume, combined with the structurally increased vascular responsiveness, provide a plausible explanation for the transition from high cardiac output to elevated vascular resistance in the evolution of hypertension. However, an explanation is also needed for the parallel decrease of sympathetic tone. As hypertension advances, sympathetic activity is less evident. In a review of literature, Goldstein ${ }^{35}$ found venous plasma norepinephrine to be elevated only in younger patients with borderline hypertension. Similar conclusions can be derived from the work of Esler et al. ${ }^{15}$ Norepinephrine spillover rates are characteristically increased in younger patients, whereas spillover rates in older hypertensives are similar to those in normotensive individuals. Cardiac output and heart rate differences between borderline hypertensives and normotensive individuals decline with age. In our first study, a significant elevation of cardiac output and heart rate was seen only in patients younger than 45 years. $^{5}$

Epidemiologic and clinical data strongly suggest that patients with borderline hypertension eventually develop a more severe, established hypertension. Why would the sympathetic tone change from elevated to apparently normal values during transition from borderline hypertension to established hypertension? We recently postulated an hypothesis that provides the necessary framework to explain this transition. ${ }^{36}$ The hypothesis is based on numerous observations about the "blood-pressuresccking" property of the CNS. Whereas the ultimate purpuse of all circulatory control systems is to provide an adequate blood flow, it appears that the CNS subserves the circulation by regulating the blood pressure. This conclusion is reached from the analysis of numerous central blood pressure responses (mental stress, response to noise, isometric exercise, stellate ganglion stimulation, hindquarter compression in dogs). In all these situations it is possible to alter the underlying hemodynamics without changing the blood pressure response. For example, the increase of cardiac output with mental stress can be abolished with $\beta$-adrenergic blockade without affecting the magnitude of the blood pressure response. ${ }^{37}$ Similarly, hemodynamic response to noise, normally associated with increased vascular resistance, can be converted with 
vasodilators into increased cardiac output without affecting the magnitude of the blood pressure response..$^{38} \mathrm{It}$ is important to realize that during these pharmacologic interventions the underlying amount of cardiac output varied a great deal, but the blood pressure response was precisely regulatcd. This implies that feedback to the CNS must be related to the achieved pressure. If this is true, then the amount of neuronal firing needed to achieve a given pressure greatly depends on the responsiveness of peripheral organs. Due to an altered wall to lumen ratio, the arterioles in advanced hypertension are hyperresponsive to all vasoconstrictive stimuli, ${ }^{39}$ and less sympathetic tone is needed to achieve the same blood pressure elevation. Within the context of the blood-pressure-seeking property of the brain, the observed sequence of events in borderline and advanced hypertension is to be expected. Accepting that as hypertension advances the vascular responsiveness becomes enhanced, if the CNS seeks a higher pressure, it can achieve that pressure increase in advanced hypertension with less sympathetic firing. The primary mechanism of blood pressure elevation may still be neurogenic, but due to changes of the vascular responsiveness, the absolute sympathetic tone will not be increased.

\section{CAUSES OF AUTONOMIC ABNORMALITY IN HYPERTENSION}

Behavioral research into the causes of enhanced sympathetic tone in hypertension took two directions. The "reactivity" research is based on observations of increased responsiveness to mental stress. There is substantial evidence that blood pressure response to mental stress is exaggerated in patients with borderline hypertension ${ }^{40}$ and in offspring of hypertensive parents. ${ }^{41}$ However, the responses to physical stressors in borderline hypertension are normal. ${ }^{42}$ Also, blood pressure oscillation during 24hour blood pressure monitoring is not exaggerated in borderline hypertension. ${ }^{43}$ This speaks against a generalized CNS inability to regulate ANS blood pressure oscillations in hypertension. The notion that permanent hypertension occurs through a summation of exaggerated and frequent pressor episodes has no support in actual fact.

The other direction of research into behavioral causes assumes that the increased sympathetic tone is a product of an habitual style of interaction with the environment. Subjects with certain personality patterns may be more alert and vigilant, and this might cause a steady (not episodic) central activation of the sympathetic nervous system. A tendency to "hold anger in" has been described in subjects with higher blood pressure readings. ${ }^{44}$ Inability to express anger is a particular characteristic of subjects with "sustained" (both at home and in the physician's office) blood pressure elevation, whereas increased anxiety is found in patients with "office" hypertension. ${ }^{45}$ Subjects with borderline or mild hypertension are also known to be submissive to other people. ${ }^{13,46}$ Unfortunately, these personality factors have not been evaluated in a prospective fashion to determine whether they can be found prior to the development of elevated blood pressure values.

Our recent studies in Tecumseh ${ }^{47}$ suggest that the sympathetic activation in borderline hypertension is part of a very complex pathophysiologic picture. In addition to having faster heart rates, subjects with borderline hypertension tend to be overweight and have higher plasma insulin, cholesterol and triglyceride levels, whereas the high-density lipoproteins are decreased. Finding the primary aberration in this intimately intertwined set of abnormalities may be very difficult. For example, one recently proposed theory holds that the abnormality may reside in the dietary behavior of subjects with hypertension. Increased carbohydrate intake may lead to excessive insulin release, and this in turn may stimulate the CNS to increase the sympathetic discharge. ${ }^{48}$ Interaction between sodium sensitivity, insulin resistance and sympathetic overactivity has also been postulated. ${ }^{49}$ From a narrow frame of reference (behavioral medicine), investigations of the etiology of the increased sympathetic drive in hypertension are widening to include complex interdisciplinary research. At the present we are far from a definitive answer.

\section{REFERENCES}

1. Widimsky J, Fejfarova MH, Fejfar Z. Changes of cardiac output in hypertensive disease. Cardiologia 1957;31:381-389.

2. Eich RH, Peters RJ, Cuddy RP, Smulyan H, Lyons RH. The hemodynamics in labile hypertension. Am Heart $J$ 1962;63:188-195.

3. Sannerstedt $R$. Hemodynamic response to exercise in patients with arterial hypertension. Acta Med Scand 1966;458(suppl):1-83.

4. I und-Iohansen P. Hemodynamics in early essential hypertension. Acta Med Scand 1967;482(suppl):1-105.

5. Julius S, Conway J. Hemodynamic studies in patients with borderline blood pressure elevation. Circulation 1968:38:282-288.

6. Brod J. Hemodynamic basis of acute pressor reactions and hypertension. $\mathrm{Br}$ Heart $J$ 1963;25:227-245.

7. Julius S, Pascual AV, London R. Role of parasympathetic inhibition in the hyperkinetic type of borderline hypertension. Circulation 1971:44:413-418.

8. Anderson EA, Sinkey CA, Lawton WJ, Mark AL. Elevated sympathetic nerve activity in borderline hypertensive humans. Evidence from direct intraneural recordings. Hypertension 1989;14:177-183.

9. Esler M, Julius S, Zweifler A, Randall O, Harburg E, Gardiner H, DeQuattro V. Mild high-renin essential hypertension. Neurogenic human hypertension? $N$ Engl J Med 1977;296:405-411.

10. Esler M, Jennings G, Biviano B, Lambert G, Hasking G. Mechanism of elevated plasma noradrenaline in the course of essential hypertension. $J$ Cardiovascular Pharm 1986;8(suppl 5):S39-S43.

11. Guzzetti S, Piccaluga E, Casati R, Cerutti S, Lombardi F, Pagani M, Malliani A. Sympathetic predominance in essential hypertension: a study employing spectral analysis of heart rate variability. $J$ Hypertension 1988;6:711-717. 
12. Bohm ROB, van Baak MA, van Hooff MEJ, Mooy J, Rahn KH. Salivary flow in borderline hypertension. Klin Wschr 1985;63(suppl III):154-156. 13. Esler MD, Julius $S$, Randall $O S$, Ellis $C N$, Kashima $T$. Relation of renin status to neurogenic vascular resistance in borderline hypertension. Am J Cardiol 1975;36:708-715

14. Julius S, Esler M. Autonomic nervous cardiovascular regulation in borderline hypertension. Am J Cardiol 1975;36:685-696

15. Esler M, Jennings $G$, Lambert G. Noradrenaline release and the pathophysiology of primary human hypertension. Am J Hypertens 1989;2:140S-146S

16. Julius $S$, Pascual AV, Reilly K, London R. Abnormalities of plasma volume in borderline hypertension. Arch Intern Med 1971;127:116-119.

17. Ellis $\mathrm{CN}$, Julius $\mathrm{S}$. Role of central blood volume in hyperkinetic borderline hypertension. Br Heart $J$ 1973;35:450-455.

18. Takeshita A, Mark AL. Decreased venous distensibility in borderline hypertension. Hypertension 1979;1:202-206.

19. Julius S, Schork MA. Borderline hypertension-A critical review. J Chronic Dis 1971;23:723-754.

20. Paffenbarger RS, Jr, Thorne MC, Wing AL. Chronic disease in former college students-VIII. Characteristics in youth predisposing to hypertension in later years. Am J Epidemiol 1968;88:25-32.

21. Stamler J, Berkson DM, Dyer A, Lepper MH, Lindberg HA, Paul O, McKean H. Rhomberg P. Schoenberger JA, Shekelle RB. Stamler R. Relationship of multiple variables to blood pressure-Findings from four Chicago epidemiologic studies. In: Paul O, ed. Epidemiology and Control of Hypertension. Miami: Symposia Specialists, 1975:307-352.

22. Levy RL, Hillman CC, Stroud WD, White PD. Transient hypertension: its significance in terms of later development of sustained hypertension and cardiovascular-renal diseases. JAMA 1944;1 26:829-833.

23. Eich RH, Cuddy RP, Smulyan H, Lyons RH. Hemodynamics in labile hypertension: a follow-up study. Circulation 1966;34:299-307.

24. Safar ME, Weiss YA, Levenson JA, London GM, Milliez PL. Hemodynamic study of 85 patients with borderline hypertension. Am J Cardiol 1973;31:315319.

25. Lund Johansen P, Omvik P. Hemodynamic patterns of untreated hypertensive disease. In: Laragh JH, Brenner GM, eds. Hypertension: Pathophysiology, Diagnosis, and Management. New York: Raven Press, 1990:305-327.

26. Guyton AC, Coleman TG. Quantitative analysis of the pathophysiology of hypertension. Circ Res 1969;24-25(suppl 1):1-19.

27. Light KC, Kopeke JP, Obrist P, Willis PW IV. Psychological stress induces sodium and fluid retention in men at high risk for hypertension. Science 1983;220:429-431

28. Julius S, Pascual AV, Reilly K, London R. Abnormalities of plasma volume in borderline hypertension. Arch Intern Med 1971;127:116-119.

29. Juljus S, Randall OS, Esler MD, Kashima T, Ellis CN, Bennett J. Altered cardiac responsiveness and regulation in the normal cardiac output type of borderline hypertension. Circ Res 1975;36-37:I-199-I-207.

30. Trimarco B, Volpe M, Ricciardelii B, Picotti GB, Galva MA, Petracca R, Condorelli M. Studies of the mechanisms underlying impairment of beta-adrenoceptor-mediated effects in human hypertension. Hypertension 1983;5:584-590.
31. Buhler FR, Kiowski W, Bolli P, Muller FB, Jones RC. The $\beta$ - and $\alpha$ adrenoceptor response adaptation in hypertension development. J Cardiovascular Pharm 1987;10(suppl 4):S76-S80.

32. Folkow B. Physiological aspects of primary hypertension. Physiol Rev 1982;62:347-503.

33. Hart MN, Heistad DD, Brody MJ. Effect of chronic hypertension and sympathetic denervation on wall/lumen ratio of cerebral vessels. Hypertension 1980;2:419-428.

34. Conway J. A vascular abnormality in hypertension. A study of blood flow in the forearm. Circulation 1963;27:520-529.

35. Goldstein DS. Plasma catecholamines and essential hypertension. An analyti cal review. Hypertension 1983;5:86-99.

36. Julius $S$. The blood pressure seeking properties of the central nervous system. J Hypertension 1988;6:177-185.

37. Ulrych $\mathrm{M}$. Changes of general haemodynamics during stressful mental arithmetic and non-stressing quiet conversation and modification of the latter by betaadrenergic blockade. Clin Sci 1969;36:453-461.

38. Andren L, Hansson L. Circulatory effects of stress in essential hypertension. Acta Med Scand 1980;646:69-72.

39. Egan B, Panis R, Hinderliter A, Schork N, Julius S. Mechanism of increased alpha-adrenergic vasoconstriction in human essential hypertension. J Clin Invest 1987;80:812-817

40. Nestel PJ. Blood pressure and catecholamine excretion after mental stress in labile hypertension. Lancet 1969;1:692-694.

41. Falkner B, Kushner H, Onesti G, Angelakos E. Cardiovascular characteristics in adolescents who develop essential hypertension. Hypertension 1981;3:521 527

42. Weder AB, Julius $S$. Behavior, blood pressure variability and hypertension Psychosom Med 1985;47:406-414.

43. Mancia G, Ferrari A, Gregorini L, Parati G, Pomidossi G, Bertinieri G Grassig D, Rienzo M, Zanchetti A. Blood pressure and heart rate variabilities in normotensive and hypertensive human beings. Circ Res 1983;53:96-104

44. Harburg E, Erfurt JC, Hauenstein LS, Chape C, Schull WJ, Schork MA Socio-ecological stress, suppressed hostility, skin color, and black-white malc blood pressure. Detroit. Psychosom Med 1973;35:276-296.

45. Schneider RH, Egan BM, Johnson EH, Drobny H, Julius S. Anger and anxiety in borderline hypertension. Psychosom Med 1986;48:242-248.

46. Harburg E, Julius S, McGinn NF, McLeod J, Hoobler SW. Personality traits and behavioral patterns associated with systolic blood pressure levels in college males. $J$ Chronic Dis 1964;17:405-414.

47. Julius S, Jamerson K, Mejia A, Krause L, Schork N, Jones K. Tecumseh Blood Pressure Study: Borderline hypertension is associated with target organ changes and higher coronary risk. JAMA 1990 (in press).

48. Landsberg L. Diet, obesity and hypertension: an hypothesis involving insulin the sympathetic nervous system, and adaptive thermogenesis. $Q J$ Med 1986 61:1081-1090.

49. Rocchini AP, Key J, Bondie D, Chico R, Moorehead C, Katch V, Martin M The effect of weight loss on the sensitivity of blood pressure to sodium in obese adolescents. $N$ Engl J Med 1989;321:580-585. 